\title{
The Acoustics of Lexical Stress in Italian as a Function of Stress Level and Speaking Style
}

\author{
Anders Eriksson ${ }^{1}$, Pier Marco Bertinetto ${ }^{2}$, Mattias Heldner ${ }^{1}$, Rosalba Nodari ${ }^{2}$, Giovanna Lenoci ${ }^{2}$ \\ ${ }^{1}$ Department of Linguistics, Stockholm University, Sweden \\ ${ }^{2}$ Scuola Normale Superiore, Pisa, Italy \\ anders.eriksson@ling.su.se, heldner@ling.su.se, p.bertinetto@sns.it, r.nodari@hotmail.it, \\ lenocigiovannalibero.it
}

\begin{abstract}
The study is part of a series of studies, describing the acoustics of lexical stress in a way that should be applicable to any language. The present database of recordings includes Brazilian Portuguese, English, Estonian, German, French, Italian and Swedish. The acoustic parameters examined are $F_{0^{-}}$-level, $F_{0^{-}}$ variation, Duration, and Spectral Emphasis. Values for these parameters, computed for all vowels (a little over 24000 vowels for Italian), are the data upon which the analyses are based. All parameters are examined with respect to their correlation with Stress (primary, secondary, unstressed) and speaking Style (wordlist reading, phrase reading, spontaneous speech) and Sex of the speaker (female, male). For Italian Duration was found to be the dominant factor by a wide margin, in agreement with previous studies. Spectral Emphasis was the second most important factor. Spectral Emphasis has not been studied previously for Italian but intensity, a related parameter, has been shown to correlate with stress. $F_{0}$-level was also significantly correlated but not to the same degree. Speaker Sex turned out as significant in many comparisons. The differences were, however, mainly a function of the degree to which a given parameter was used, not how it was used to signal lexical stress contrasts.
\end{abstract}

Index Terms: speech prosody, lexical stress, Italian

\section{Introduction}

The present study is part of a series describing the acoustics of word stress in a number of typologically different languages. The goal is to develop an analysis model that may be applied to any language. We have recorded data from Brazilian Portuguese, English, Estonian, French, German, Italian and Swedish. Analyses have been published for Brazilian Portuguese, [1, 2] Estonian [3], English [4] German [5] and Swedish $[6,7]$.

All languages that have contrastive word stress have primary stress. In some languages, the stress contrast is binary; stressed or unstressed. Many languages, also have secondary stress, in which case three levels of stress must be considered.

In our studies we have found that the acoustic correlates of stress are influenced by speaking style. Word list reading tends to produce the most prototypical stress realization, typically described in lexica, whereas in spontaneous speech acoustic correlates are often reduced. Phrase reading falls somewhere in between. We therefore also study the influence of speaking style on the acoustics of word stress. The speaking styles investigated in the studies are, wordlist reading, phrase reading, and spontaneous speech.

The study of the acoustics of word stress has a long tradition. Classical studies are those by Fry in the 1950s [8]. In his study of English word stress, he found that $F_{0}$-level and variation, vowel duration and vowel amplitude correlated with word stress but not to the same degree. The findings have been confirmed in a broad sense in studies of other languages like Polish [9], French [10], Swedish [11], and Spanish [12, 13]. Amplitude has not turned out to correlate very well with stress level or perception but Spectral Emphasis, a measure related to vocal effort, has been shown to correlate with stress in studies of Dutch $[14,15]$. It has also been shown to play a role in American English [16, 17] and Swedish [6, 7, 18].

The study of the acoustics of word stress in Italian goes back a long time. Panconcelli-Calzia [19] suggested that duration, intensity and frequency jointly increase under stress, while Gemelli [20] proposed a strict hierarchy: duration $>$ frequency $>$ intensity. The first reliable studies, performed after the introduction of the Sonograph and intensity and frequency meters proposed the hierarchy duration $>$ intensity $>$ frequency [21], or a duration/frequency trade-off, with these cues operating in combination or compensating each other [22]. The precedence of duration over intensity was confirmed in [23]. Duration has been proposed as the only reliable cue in production in [24], while Bertinetto [25] found the hierarchy duration $>$ intensity $>$ frequency in perception. All subsequent studies have, with minor differences, confirmed, the relevance of duration as the most reliable acoustic stress cue in Italian. In a study of regional variation [26], duration and intensity were found to be the most salient factors. Studies of formant structure have found stressed vowels to be more peripheral [27-29]. A series of works have analysed the articulatory counterpart of stress production [27, 30-32] and found that stressed vowels show larger jaw and labial aperture.

As in our previous studies we will approach the acoustics of word stress in Italian by analysing the following parameters: $F_{0^{-}}$ level, $F_{0}$-variation, Duration, and Spectral Emphasis.

\section{Method}

To minimise the influence of variation at the segmental level, we adopted a method that produced identical speech material in all speaking styles. Each speaker was first recorded in a semispontaneous interview situation. They were free to choose the topic of the conversation. The interviews lasted 15-25 minutes. The recordings were transcribed using Praat TextGrids [33] and from these transcriptions we picked out 30 phrases were speech was fluent (i.e. no pauses, no false starts etc.) and which 
contained suitable target words of two or more syllables. The target words selected from the spontaneous recordings were not phrase initial, phrase final or focally accented. Two manuscripts were prepared, one containing the target words in isolation, and one containing the corresponding phrases. Each word and phrase occurred three times in the lists, and the order between items was randomised. Two to four weeks after the interview session the speakers were recorded again, now reading the word and phrase lists based on their own spontaneous speech.

\subsection{Speakers}

The speakers (17 female; 15 male) were recruited among students at Scuola Normale Superiore di Pisa all, except 4, speaking a variety of Tuscan Italian. They were all in the same age range (female speakers, 21-30 yrs., mean 25 yrs.; male speakers, 20-29 yrs., mean 24 yrs.).

\subsection{Recordings}

The recordings were made in a sound treated studio using Sennheiser HSP 4 cardioid headset microphones connected to a computer using the M-AUDIO ProFire 2626 audio interface. Recordings were originally sampled at $48 \mathrm{kHz} / 16$ bit but they were downsampled to $16 \mathrm{kHz} / 16$ bit for the acoustic analyses.

\subsection{Parameters used in the acoustic analyses}

Fundamental frequency level is here defined as the $F_{0}$ median in the vowel in order to minimize the influence of outliers. The median is measured in semitones relative to $1 \mathrm{~Hz}$.

Fundamental frequency variation is defined as the Standard Deviation of $F_{0}$ in semitones.

Duration is measured in ms.

In these analyses we used a simplified version of the Spectral Emphasis.

Spectral Emphasis $(\mathrm{dB})=\mathrm{SPL}_{\text {full }}-\mathrm{SPL}_{0}$

$\mathrm{SPL}_{\text {full }}$ is the SPL of the full spectrum in a given segment and $\mathrm{SPL}_{0}$ is the SPL of the low-pass filtered segment using a cutoff frequency of $1.5 * F_{\text {Omean }}$ at $18 \mathrm{~dB}$ /octave (see [34]).

The use of the semitone scale for frequency means that we may expect the variation to be approximately the same for male and female speakers. The semitone scale also reduces skew. Using a log scale tends to make the distribution more normal. For this reason, we express duration as $\log _{2}(\mathrm{~ms})$. Log-scales are thus used for all parameters.

\subsection{Fixed factors used in the statistical analyses}

Sex: Male, Female

Stress: Unstressed, Secondary, Primary

Style: Spontaneous, Phrase, Word

\subsection{Extracting the parameter values}

The parameter values were extracted using a Praat script specifically designed for the purpose. The script extracted a large number of parameters used in preliminary tests. Here we will only consider the parameters described in 2.3.

In preparation for applying the script, all recordings were transcribed in Praat TextGrids using four tiers; Phrase, Word, Segment and Stress level. The TextGrid files together with the sound files were used to extract the above-mentioned values segment by segment. The output from the script was a table were each line in the table contained the acoustic data segment by segment together with its phonological symbol, type (vowel/consonant), and stress level (primary, secondary, unstressed). Stress level annotation was based on a recognised pronunciation dictionary [35]. In the analyses presented here only the vowels in the target words have been considered.

\subsection{Database used in the analyses}

The procedure described in 2.5 gave us a database of parameter values for about 24000 vowels in total. The number of vowels per speaker group (male/female) is about 11000 and 13000 respectively. The exact numbers vary slightly depending on the analysed parameter.

\section{Results}

\subsection{Fundamental frequency level}

As we may see in Figure 1 , the basic patterns of $F_{0}$-level in the vowel as a function of stress level are very similar for male and female speakers. For this parameter we know, however, that male and female speakers will differ in overall $F_{0}$-levels. The overall means for the female and male speakers are 91.45 semitones and 83.98 semitones $(197 \mathrm{~Hz}$ and $128 \mathrm{~Hz})$ respectively, corresponding to a mean difference of 7.47 semitones between the groups. In order to make the analyses of between-subjects effects including Sex more meaningful, we equalized the mean $F_{0}$-level by subtracting 7.47 semitones from each data point in the female data. A Univariate ANOVA using the equalized $F_{0}$ values as the dependent variable and Stress, Sex and Style as fixed factors showed significant main effects of Stress $[\mathrm{F}(2,24253)=30.2 ; \mathrm{p}<.001]$, Sex $[\mathrm{F}(2,24253)=15.0 ; \mathrm{p}$ $<.001]$, and Style $[\mathrm{F}(2,24253)=325.6 ; \mathrm{p}<.001]$, as well as significant interactions between $S e x$ and Stress $[\mathrm{F}(2,24253)=10.4 ; \mathrm{p}<.001]$, Sex and Style $[\mathrm{F}(2,24253)=10.2$ and between Stress and Style $[\mathrm{F}(4,24253)=171.9 ; \mathrm{p}<.001]$. The interactions between Sex, Style and Stress is not significant. The explained variance of this model is $8.3 \%$.

Effects of stress level: Unstressed and secondary stressed vowels have almost identical $F_{0}$-levels while primary stressed ones are significantly lower ( $5.5 \mathrm{~Hz}$ if converted to $\mathrm{Hz}$ ). If we look at female and male speakers separately we find the same pattern but the difference is greater in the female data $(6.4 \mathrm{~Hz}$ vs. $4.5 \mathrm{~Hz}$ ), hence the significant interaction between sex and stress.

Effects of speaking style: $F_{0}$-level varies significantly with style with spontaneous speech producing the lowest levels and phrase reading the highest. If we look at the female and male speakers separately we find that the range is somewhat higher for the male speakers $(18 \mathrm{~Hz}$ vs. $13 \mathrm{~Hz})$ which accounts for the interaction between style and sex.

\subsection{Fundamental frequency variation}

A Univariate ANOVA with $F_{0}$ standard deviation (in semitones) as dependent variable, and the same independent variables as in the model for $F_{0}$-level shows significant main effects of Stress $[\mathrm{F}(2,23954)=29.5 ; \mathrm{p}<.001]$, Sex $[\mathrm{F}(1$, $23954)=28.3 ; \mathrm{p}<.001]$ and Style $[\mathrm{F}(2,23954)=137.1 ; \mathrm{p}<.001]$, as well as an interaction between Stress and Sex that only just reached significance $[F(2,11004)=3.1 ; p=.042]$. The other interactions are not significant. The explained variance for this model is $3.3 \%$. 


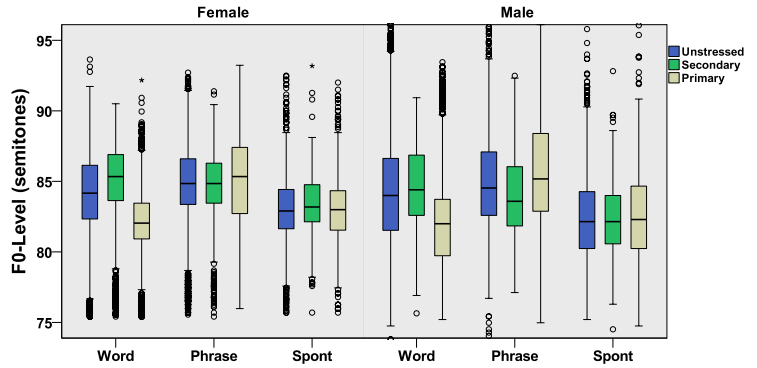

Figure 1: Fundamental frequency level as a function of speaking style and stress level.

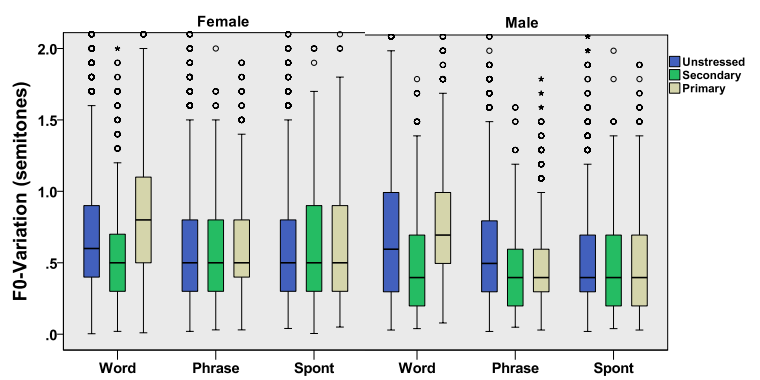

Figure 2: Fundamental frequency variation as a function of speaking style and stress level.

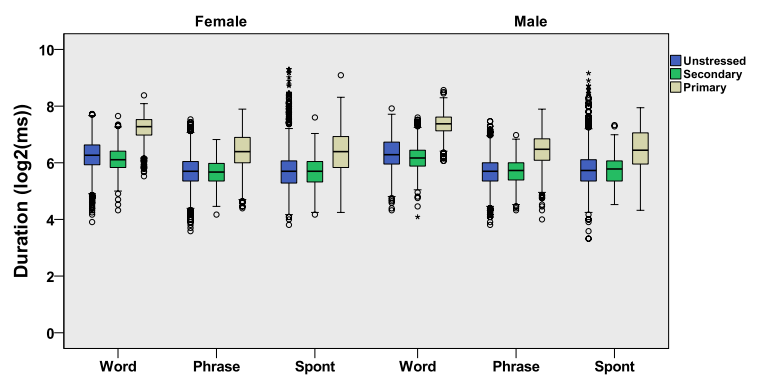

Figure 3: Vowel duration as a function of speaking style and stress level.

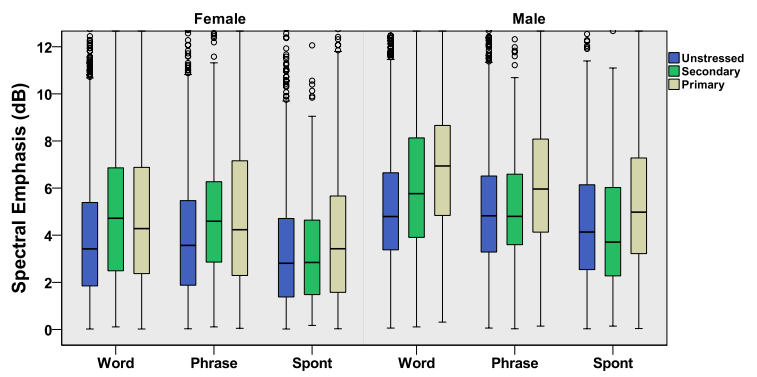

Figure 4: Spectral Emphasis as a function of speaking style and stress level.
Effects of stress level: The significant effect of Stress is primarily due to the fact that $F_{0}$-variation is markedly smaller in secondary stressed vowels. Looking at female and male speakers separately, we find that the secondary stressed vowels are the least varied in both speaker groups but that the primary stressed vowels are the most varied in the female groups and the unstressed ones in the male group. Female speakers also show generally higher variation than male speakers $(0.684$ vs. 0.668 semitones; $p=0.039$ ). This is the explanation for the significant interaction between Stress and Sex.

Effects of speaking style: Examining the effects of speaking style, we find that the $F_{0}$-variation is significantly greater in word list reading than in spontaneous speech and phrase reading $(0.77,0.60,0.59$ semitones respectively). The latter difference is not significant. If we look at male and female speakers separately we find exactly the same pattern. The significant interaction between Sex and Style is therefore caused only by the generally somewhat greater variation in the female group. The interaction between Style and Stress is caused by a combination of the above mentioned factors.

\subsection{Duration}

A Univariate ANOVA with duration of the vowel (expressed as the binary logarithm of duration in $\mathrm{ms}$ ) as dependent variable, and the same independent variables as in the other models shows significant main effects for Stress $[\mathrm{F}(2,24654)=4225 ; \mathrm{p}$ $<.001]$, Style $[\mathrm{F}(2,24654)=2595 ; \mathrm{p}<.001]$ and Sex $[\mathrm{F}(1,24654)=23.4 ; \mathrm{p}=.015]$. In addition, there are significant interactions between Stress and Style $[\mathrm{F}(2,24654)=95.8 ; \mathrm{p}<$ $.001]$; Stress and Sex $[\mathrm{F}(2,24654)=5.0 ; \mathrm{p}=.007]$ and Sex and Style $[\mathrm{F}(2,24654)=3.6 ; \mathrm{p}<.028]$. The explained variance for this model is $45.8 \%$.

Effects of stress level: Stress level has a significant effect on vowel duration but primarily between the primary stressed vowels and the unstressed and secondary stressed ones. If we express the mean durations in milliseconds, they are 64, 61, and $116 \mathrm{~ms}$ for unstressed, secondary stressed and primary stressed vowels, respectively. The significant effect of Sex is due to longer mean durations for the male speakers ( $76 \mathrm{~ms}$ vs. $73 \mathrm{~ms}$ ). If we look at the details, we may see that the difference is caused by the markedly longer primary stressed vowels in the male group $(120 \mathrm{~ms}$ vs. $113 \mathrm{~ms})$ which explains the significant interaction between Stress and Sex.

Effects of speaking style: Style also makes a significant difference. The main difference is between word list reading (92 $\mathrm{ms})$ and the other two styles, phrase reading $(59 \mathrm{~ms})$ and spontaneous speech $(61 \mathrm{~ms})$, but all comparisons are statistically significant. The moderate interaction between $\mathrm{Sex}$ and Style is caused by the fact that whereas mean durations in spontaneous speech and phrase reading are almost identical for male and female speakers, the duration in wordlist reading is longer for male speakers ( $95 \mathrm{~ms}$ vs. $90 \mathrm{~ms}$ ).

\subsection{Spectral Emphasis}

A Univariate ANOVA with spectral emphasis in the vowel (in $\mathrm{dB}$ ) as dependent variable, and otherwise the same independent variables as in the other models shows significant main effects of Stress $[\mathrm{F}(2,24654)=311 ; \mathrm{p}<.001]$, Style $[\mathrm{F}(2,24654)=164$; $\mathrm{p}<.001]$ and $\operatorname{Sex}[\mathrm{F}(1,24654)=580 ; \mathrm{p}<.001]$. In addition, there are significant interactions between Sex and Style [F(2, 24654) $=17.2 ; \mathrm{p}<.001]$, Sex and Stress $[\mathrm{F}(2,24654)=18.5 ; \mathrm{p}<.001]$, Stress and Style $[\mathrm{F}(2,24654)=15.8 ; \mathrm{p}<.001]$ and Sex, Style 
and Stress $[\mathrm{F}(2,24654)=3.7 ; \mathrm{p}<.01]$. Explained variance is $10.2 \%$.

Effects of stress level: Stress level has a significant effect on Spectral Emphasis. The mean levels for unstressed, secondary stressed and primary stressed vowels are $4.3 \mathrm{~dB}, 5.1$ $\mathrm{dB}$ and $5.5 \mathrm{~dB}$ and all differences are statistically significant (p $<0.001$ ). If male and female speakers are tested separately, the secondary vs. primary difference is not significant for the female speakers. Male speakers have on average 1.3 dB higher Spectral Emphasis. The increment in spectral emphasis from unstressed to primary stressed is also somewhat larger for male speakers $(1.5 \mathrm{~dB}$ vs. $1.0 \mathrm{~dB})$. This explains the interaction between Stress and Sex.

Effects of speaking style: Style has a corresponding effect on Spectral Emphasis increasing from $4.1 \mathrm{~dB}$ to $4.9 \mathrm{~dB}$ in three significantly different steps. If male and female speakers are analysed separately, the same pattern is found except that there is no difference between phrase and word list reading for female speakers. The increase from spontaneous to word list is also somewhat less for the female speakers $(0.7 \mathrm{~dB}$ vs. $1.0 \mathrm{~dB})$. This explains the interaction between Style and Sex. For male speakers the three steps are significantly different for stress as well as style. This explains the three-way interaction Sex, Style and Stress.

\section{Discussion}

\subsection{Fundamental frequency level}

Fundamental frequency level has been identified as an acoustic correlate of stress in Italian as pointed out in the introduction. The results in our study agree with these earlier findings although the effect of stress level on $F_{0}$-level is moderate with an explained variance of $8.3 \%$. We also found, somewhat surprisingly, that the primary stressed vowels had generally lower $F_{0}$-level. This may be due to the fact that words that carry the last sentence accent (i.e., the last accent in a sentence) are produced at a significantly lower $F_{0}$-level in declarative sentences. The dependency of $F_{0}$ on intonation considerably weakens the contribution of this parameter. We found spontaneous speech to produce the lowest levels and phrase reading the highest.

\subsection{Fundamental frequency variation}

Our results show a minimal effect of stress level on $F_{0^{-}}$variation and the effect is primarily caused by less variation in the secondary stressed vowels. This is the case in both speaker groups. The results confirm the dubious status of secondary stress in Italian, as proposed by Bertinetto [25] where a difference is made between "rhythmical" stress and "secondary" stress proper. The latter only occurs in compounds and has a true phonological status; the former only occurs on polysyllables in hyperarticulated speech and may shift from one syllable to another depending on the context. Female speakers show generally higher variation than male speakers. $F_{0^{-}}$ variation is also, as one might expect, significantly greater in word list reading than in the other two speaking styles.

\subsection{Duration}

Duration is the factor that is by far the most affected by Stress. Explained variance is $45.8 \%$. The effect is primarily between primary stressed vowels and the unstressed and secondary stressed ones although the differences between the three levels are all significant both for all speakers pooled and for male and female speakers analysed separately. Male speakers have significantly longer mean durations, but again the difference is mainly due to longer primary stressed vowels. Style also affects duration. Word list reading produces the longest vowels.

\subsection{Spectral Emphasis}

Spectral Emphasis also turned out to be a reliable correlate of word stress. With an explained variance of $10.2 \%$ it comes second only to Duration. For all data pooled, Spectral Emphasis increases gradually from unstressed to primary stressed and all differences are significant. Male speakers produce $1.3 \mathrm{~dB}$ higher Spectral Emphasis on average. The increment from unstressed to primary stressed is also greater for male speakers. Spectral Emphasis in Italian has not been studied in any previous study. There is a small but significant correlation between Spectral Emphasis and Duration. Spectral Emphasis is a vocal effort related measure and it makes sense to assume that applying more effort requires more time. Our present data do not, however, make it possible to test this hypothesis.

\section{Conclusions}

Studies of Italian have often ranked the acoustic parameters: Duration, Intensity, Frequency. If we go by the degree of explained variance our ranking is basically the same -Duration (45.8\%), Spectral Emphasis $(10.2 \%)$, and $F_{0}$-level $(8.3 \%)$. The dominant role of Duration found in previous studies also receives strong confirmation in our results.

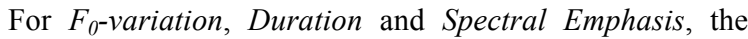
effect of Style is most marked in word list reading. This may at least partly be due to the fact that in this speaking style phrase prosody inevitably interacts with word prosody to a greater extent than in the other speaking styles. We have not found a suitable way of handling this possible asymmetry in the present data.

The present study shows Italian to be yet another language where Spectral Emphasis plays a significant role. This has not, as far as we are aware, been observed before. Intensity, which is related to Spectral Emphasis, has been studied, however, and found to correlate with stress. In our previous studies of other languages, we have also found male speakers to produce greater Spectral Emphasis e.g. [2, 4, 6]. The difference varies between languages but is on the same order of magnitude $1-3 \mathrm{~dB}$.

An observation we made in our analysis of English, was that the male and female speakers produced the stress contrast basically the same way. The same observation may be made in the Italian data analysed here. This may sound contradictory given that in all the analyses above Sex was found to be a significant factor. We may resolve this apparent contradiction by looking at the results concerning Spectral Emphasis. Both speaker groups signal stress variation the same way - by varying Spectral Emphasis as a function of stress level - but the range of variation is somewhat smaller in the female group. Similar observations may be made for the other parameters

\section{Acknowledgements}

The research programme has been funded by the Swedish Research Council (VR) project $A$ typology for word stress and speech rhythm based on acoustic and perceptual considerations, under grant 2007-2301. 


\section{References}

[1] Barbosa, P. A., Eriksson, A., and Åkesson, J., "Crosslinguistic similarities and differences of lexical stress realisation in Swedish and Brazilian Portuguese," in Proc. Nordic Prosody 2012, Frankfurt am Main: Peter Lang, 2013, pp. 97-106.

[2] Barbosa, P. A., Eriksson, A., and Åkesson, J., "On the robustness of some acoustic parameters for signalling word stress across styles in Brazilian Portuguese," in Proc. Interspeech 2013, Lyon, 2013, pp. 282-286.

[3] Lippus, P., Asu, E. L., and Kalvik, M.-L., "An acoustic study of Estonian word stress," in Proc. Speech Prosody 2014, Dublin, 2014, pp. 232-235.

[4] Eriksson, A. and Heldner, M., "The acoustics of word stress in English as a function of stress level and speaking style," in Proc. Interspeech 2015, Dresden, 2015, pp. 4145.

[5] Behrens, J., "Die Prosodie des Wortakzentes in Abhängigkeit von Akzentlevel und Sprechstil," BA Thesis, Philosophischen Fakultät, Christian-AlbrechtsUniversität zu Kiel, 2013.

[6] Eriksson, A., Barbosa, P. A., and Åkesson, J., "Word stress in Swedish as a function of stress level, word accent and speaking style," in Proc. Nordic Prosody 2012, Frankfurt am Main: Peter Lang, 2013, pp. 127-136.

[7] Eriksson, A., Barbosa, P. A., and Åkesson, J., "The acoustics of word stress in Swedish: A function of stress level, speaking style and word accent," in Proc. Interspeech 2013, Lyon, 2013, pp. 778-782.

[8] Fry, D. B., "Duration and intensity as physical correlates of linguistic stress," Journal of the Acoustical Society of America, vol. 27, pp. 765-768, 1955.

[9] Jassem, W., Morton, J., and Steffen-Bartóg, M., "The perception of stress in synthetic speech-lke stimuli by Polish listeners," Speech Analysis and Synthesis, vol. 1, pp. 289-308, 1968.

[10] Benguerel, A. P., "Physiological correlates of stress in French (Correlats physiologiques de l'accent en francais)," Phonetica, vol. 27, pp. 21-35, 1973.

[11] Fant, G. and Kruckenberg, A., "Notes on stress and word accent in Swedish," in STL/QPSR, vol. 2-3, 1994, pp. 125 144.

[12] Díaz-Campos, M., "The Phonetic Manifestation of Secondary Stress in Spanish," in Hispanic Linguistics at the Turn of the Millennium, Somerville, MA: Cascadilla, 2000, pp. 49-65.

[13] Vargas-Calderon, R., "Acoustic Analysis of Stress in the Spanish Spoken in Costa Rica (Analyse acoustique de l'accent de l'espagnol parle au Costa Rica)," Travaux de l'Institut de Phonetique de Strasbourg, vol. 18, pp. 1-23, 1986.

[14] Sluijter, A. M. C., Phonetic Correlates of Stress and Accent. The Hague: Holland Academic Graphics, 1995.

[15] Sluijter, A. M. C. and van Heuven, V. J., "Spectral balance as an acoustic correlate of linguistic stress," Journal of the Acoustical Society of America, vol. 100, pp. 2471-2485, 1996.

[16] Campbell, N. and Beckman, M. E., "Stress, prominence, and spectral tilt," in Intonation: Theory, Models, and Applications Athens, 1997, pp. 67-70.

[17] Campbell, N. and Beckman, M. E., "Accent, stress, and spectral tilt," Journal of the Acoustical Society of America, vol. 101, p. 3195, 1997.
[18] Heldner, M., "On the reliability of overall intensity and spectral emphasis as acoustic correlates of focal accents in Swedish," Journal of Phonetics, vol. 31, pp. 39-62, 2003.

[19] Panconcelli-Calzia, G., "Über das Verhalten von Dauer und Höhe im Akzent," Vox, vol. 27, pp. 127-148, 1912.

[20] Gemelli, A., La strutturazione psicologica del linguaggio studiata mediante l'analisi elettroacustica: Città del Vaticano, 1950.

[21] Rossi, M., "Sur la hiérarchie des paramètres de l'accent," in Proc. ICPhS 1970, Praha, 1970, pp. 779-786.

[22] Ferrero, F., "Caratteristiche acustiche dei fonemi vocalici italiani," Parole e Metodi, vol. 3, pp. 9-32, 1972.

[23] Fava, E. and Magno-Caldognetto, E., "Studio sperimentale delle caratteristiche elettroacustiche delle vocali toniche e atone in bisillabi italiani," in Atti del Convegno Internazionale di Studi di fonetica e fonologia, R. Simone, et al., Eds. Rome: Bulzoni, 1976, pp. 35-79.

[24] Bertinetto, P. M., Strutture prosodiche dell'italiano. Accento, quantità, sillaba, giuntura, fondamenti metrici. Firenze: Accademia della Crusca, 1981.

[25] Bertinetto, P. M., "The perception of stress by Italian speakers," Journal of Phonetics, vol. 8, pp. 385-395, 1980.

[26] Romito, L., "Cenni sui correlati elettroacustici dell'accento in alcune varietà di italiano," in Atti del convegno IV Giornate di Studio del Gruppo di Fonetica Sperimentale (G.F.S.), Torino, 1994, pp. 107-119.

[27] Vayra, M. and Fowler, C. A., "Declination of supralaryngeal gestures in spoken Italian," Phonetica, vol. 49, pp. 48-60, 1992.

[28] Farnetani, E. and Vayra, M., "The role of prosody in the shaping of articulation in Italian CV syllables," in Proc. ESCA Tutorial and Research Workshop on Speech Production Modeling, Autrans, 1996, pp. 9-12.

[29] Vayra, M., Avesano, C., and Fowler, C. A., "On the phonetic bases of vowel-consonant coordination in Italian: a study of stress and "Compensatory Shortening"," in Proc. ICPhS 1995, vol. I San Francisco, USA, 1999, pp. 495-498.

[30] Farnetani, E. and Faber, A., "Tongue-jaw coordination in vowel production: isolated words vs connected speech," Speech Communication, vol. 11, pp. 401-410, 1992.

[31] Magno-Caldognetto, E., Vagges, K., and Zmarich, C., "Visible articulatory characteristics of the Italian stressed and unstressed vowels," in Proc. ICPhS 1995, vol. I Stockholm, 1995, pp. 366-369.

[32] Vayra, M. and Fowler, C. A., "The interplay of stress, coarticulation, vowel height and vowel position in Italian," in Proc. ICPhS 1987, vol. IV Tallinn, Estonia: Academy of Sciences of the Estonian S.S.R, 1987, pp. 24-27.

[33] Boersma, P. and Weenink, D. (2015), "Doing Phonetics by Computer"

[34] Traunmüller, H. and Eriksson, A., "Acoustic effects of variation in vocal effort by men, women, and children," Journal of the Acoustical Society of America, vol. 107, pp. 3438-3451, 2000.

[35] Dizionario italiano multimediale e multilingue d'Ortografia e di Pronunzia [Online]. Available: http://www.dizionario.rai.it/ 